\title{
A CONSTITUIÇÃO \\ FEDERAL DE 1988 E O \\ MULTICULTURALISMO: \\ GARANTIA AO \\ TERRITÓRIO COMO \\ DIREITO FUNDAMENTAL \\ COLETIVO DOS POVOS \\ E DAS COMUNIDADES \\ TRADICIONAIS
}

THE 1988 FEDERAL CONSTITUTION AND MULTICULTURALISM: GUARANTEE OF ACCESS TO TERRITORY AS A COLLECTIVE FUNDAMENTAL RIGHT OF PEOPLES AND

TRADITIONAL COMMUNITIES

LA CONSTITUCIÓN FEDERAL DE 1988 Y EL MULTICULTURALISMO: LA GARANTÍA AL TERRITORIO COMO DERECHO FUNDAMENTAL COLECTIVO DE LOS PUEBLOS Y DE LAS COMUNIDADES TRADICIONALES

Syglea Rejane Magalhães Lopes ${ }^{1}$

1 Universidade da Amazônia. Belém, Pará, Brasil. Professora Titular do Instituto de Ciências Jurídicas - ICJ da Universidade da Amazônia. E-mail: syglea@gmail.com. 
Resumo: Este estudo examina a garantia do direito aos territórios por parte de povos e comunidades tradicionais à luz da Constituição Federal de 1988 e das normas infraconstitucionais. A abordagem privilegia a Amazônia Legal e se concentra em três categorias de povos e comunidades tradicionais: indígenas, remanescentes de quilombos e extrativistas tradicionais, localizadas em unidades de conservação e em projeto de assentamento agroextrativista. Faz-se um exame crítico dos institutos jurídicos que garantem aos povos e às comunidades tradicionais o reconhecimento aos territórios. Os resultados da pesquisa enfatizam a importância da normatização e da regulamentação, com base no direito coletivo do reconhecimento aos territórios por parte de povos e comunidades tradicionais, considerando-se que o meio ambiente cultural compõe o patrimônio ambiental nacional - meio ambiente ecologicamente equilibrado.

Palavras-chave: Multiculturalismo. Povos e Comunidades Tradicionais. Patrimônio Ambiental Cultural. Direitos Coletivos.

Abstract: This study examines the right of access to territory, for traditional peoples and communities, in light of the Brazilian Constitution of 1988 and the infraconstitutional norms. The approach emphasizes the Legal Amazon and focuses on three categories of peoples and traditional communities: indigenous, remnant quilombo and traditional extractivist communities, located in conservation units (RESEX, FLONA and RDS) and an agro-extractivist settlement (PAE). It makes a critical examination of legal institutions that guarantee access to traditional territories, for people and traditional communities. The results of the survey highlight the importance of normatization and regulation, based on the collective right of access to the territories by traditional peoples and communities, considering that they are part of the national environmental heritage, i.e. an ecologically balanced environment.

Keywords: Multiculturalism. People and traditional communities. Cultural environmental patrimony. Collective rights.

Resumen: Este estudio examina la garantía del derecho a los territorios por parte de pueblos y comunidades tradicionales a 
la luz de la Constitución Federal de 1988 y de las normas infraconstitucionales. El abordaje privilegia la Amazonia Legal y se concentra en tres categorías de pueblos y comunidades tradicionales: indígenas, remanecientes de quilombos y extractivistas tradicionales, ubicadas en unidades de conservación y en proyecto de asentamiento agroextractivista. Se hace un examen crítico de los institutos jurídicos que garantizan a los pueblos y a las comunidades tradicionales el reconocimiento a los territorios. Los resultados de la investigación enfatizan la importancia de la normalización y de la reglamentación, con base en el derecho colectivo del reconocimiento a los territorios por parte de pueblos y comunidades tradicionales, considerando que el medio ambiente cultural compone el patrimonio ambiental nacional, es decir, el medio ambiente ecológicamente equilibrado.

Palabras clave: Multiculturalismo. Pueblos y Comunidades Tradicionales. Patrimonio Ambiental Cultural. Derechos Colectivos.

\section{INTRODUÇÃO}

questão do multiculturalismo é temática importante quando se
pretende discutir sobre os avanços da Constituição de $1988 \mathrm{em}$
relação ao reconhecimento a povos e comunidades tradicionais do direito ao território. Entretanto, antes de se adentrar mais profundamente a conexão entre tais pontos, convêm esclarecer o que é multiculturalismo.

Para o presente artigo, o multiculturalismo será abordado como teoria de caráter normativo, que conforme Silva² refere-se a uma: "[...] proposta de solução para os problemas provenientes da convivência entre as pessoas e os diferentes grupos culturais que buscam na coexistência conjunta, manter suas pautas culturais e sociais num mesmo território."

2 SILVA, Larissa Tenfen. O multiculturalismo e a política de reconhecimento de Charles Taylor. In: Novos Estudos Jurídicos. Universidade do Vale do Itajaí, Curso de Mestrado em ciências Jurídicas, v. 11, n. 2. 2006. p. 314. Em: < http://www6.univali.br/seer/index.php/ nej/article/ view/440/382 >. Acesso em: 24 maio 2015. 
Ainda, como base para discussão, é importante trazer à baila a reflexão feita pelos autores Pinto e Menezes ${ }^{3}$, para quem o Direito tradicional, considerado como o direito racional e ao mesmo tempo universal, cuja produção pode ser concentrada em um único centro de produção jurídica - o Estado, já não atende mais as demandas da sociedade atual.

Ademais, Pinto e Menezes ${ }^{4}$ discorrem sobre a crítica realizada por Boaventura de Sousa Santos quanto ao triunfo da ideologia liberal, em que o Direito é um componente de uma estrutura econômica capitalista, servindo de base para o conceito de ciência que passa a ter como prioridade a regulação do mercado e da sociedade. E, em razão disso, concluem que a "humanidade se encontra em uma era de transição de paradigmas, não mais servindo a doutrina positivista (liberal) para oferecer qualquer resposta às contradições e às mazelas sociais [...]."

Lopes $^{5}$ também se subsidia em Boaventura de Sousa Santos que analisa o impacto da globalização em relação à cultura utilizada: "[...] como estratégia econômica e política para manter o sistema capitalista" e aponta a necessidade de se pensar novas formas de globalização. Nesse sentido, lançou mão de dois conceitos utilizados por este autor - o cosmopolitismo e o patrimônio comum da humanidade.

Quando Santos ${ }^{6}$ reporta-se ao cosmopolitismo, diz: "O cosmopolitismo que defendo é o cosmopolitismo do subalterno em luta contra a subalternização." O autor compreende que há uma solidariedade transnacional entre os grupos explorados, oprimidos ou excluídos pela globalização, independente de tratar-se de populações hiperlocalizadas ou hipertransnacionais.

3 PINTO, Felipe Chiarello de Souza; MENEZES, Daniel Francisco Nagao. O direito e o multiculturalismo: a tensão entre regulação e emancipação. In: Novos Estudos Jurídicos. Universidade do Vale do Itajaí, Curso de Mestrado em ciências Jurídicas. v. 18, n. 1. p. 2013, 64-65. Em: <http://www6.univali.br/seer/index.php/nej/article/view/4484>. Acesso em: 24 maio 2015.

4 PINTO, Felipe Chiarello de Souza; MENEZES, Daniel Francisco Nagao. O direito e o multiculturalismo: a tensão entre regulação e emancipação. p. 64-65

5 LOPES, Syglea Rejane Magalhães Lopes. Reconhecimento aos índios do direito originário sobre as terras que tradicionalmente ocupam: raposa serra do sol. In: Revista da Faculdade de Direito da UFG. v. 37, no. 2. Goiás: UFG, 2013. p. 67. Em: < http://revistas. ufg.br/index. php/revfd/article/view/24055/16357>. Acesso: 24 maio 2015.

6 SANTOS, Boaventura de Sousa. Reconhecer para libertar: os caminhos do cosmopolitismo multicultural. p. 437. 
Referente ao patrimônio comum da humanidade continua Lopes ${ }^{7}$

[...] Santos (2003, p. 437) diz abarcar temas que "[...] só fazem sentido em relação ao globo na sua totalidade [...]". Um exemplo são as questões ambientais, nas quais se incluem os povos e comunidades tradicionais e, portanto os povos indígenas. De acordo com nossa segunda premissa, os direitos humanos constituem um roteiro emancipatório. Defender essa premissa implica necessariamente, segundo Santos (2003, p. 444), adotar a hermenêutica diatópica e um multiculturalismo progressista.

Ainda de acordo com Santos ${ }^{8}$ ao trabalhar o multiculturalismo, reportase à hermenêutica diatópica, a qual parte do pressuposto de que "[...] os topoi [premissas de argumentação] de uma dada cultura, por mais fortes que sejam, são tão incompletos quanto a própria cultura a que pertencem". Nesse sentido, o objetivo da hermenêutica diatópica é ampliar a conscientização dessa incompletude. Demonstrando, portanto, a necessidade de reconhecimento da diversidade cultural bem como de que esta só sobreviverá se o Direito trabalhar a emencipação da ciência e da sociedade.

É nesse contexto que se propõe a estudar o reconhecimento do direito ao território por parte dos povos e das comunidades tradicionais, lançando mão do multiculturalismo progressista, por suscitar segundo Lopes:

as questões da diferença, do lugar e dos direitos das minorias em relação à maioria, da identidade e do seu reconhecimento. Daí a importância de utilizar a hermenêutica diatópica, que pressupõe o imperativo transcultural que garantirá a povos e comunidades tradicionais o direito de serem diferentes, pois, caso contrário, a igualdade descaracterizálos-á.

Nesse sentido, o presente estudo objetiva realizar uma análise comparativa e crítica das normas jurídicas relativas ao reconhecimento do direito de povos e das comunidades tradicionais aos territórios, com o intuito de demonstrar que o direito à cultura - em especial, o direito à sociodiversidade - impõe ao Estado

7 LOPES, Syglea Rejane Magalhães Lopes. Reconhecimento aos índios do direito originário sobre as terras que tradicionalmente ocupam: raposa serra do sol. p. 68.

8 SANTOS, Boaventura de Souza. Reconhecer para libertar: os caminhos do cosmopolitismo multicultural. p. 444.

9 LOPES, Syglea Rejane Magalhães Lopes. Reconhecimento aos índios do direito originário sobre as terras que tradicionalmente ocupam: raposa serra do sol. p. 68. 
o dever de proteger os territórios tradicionais por meio de novos institutos e instrumentos que nascem com base no Direito Coletivo.

Essa abordagem mantém relação intrínseca com o socioambientalismo, que segundo Cavedon e Vieira ${ }^{10}$ :

visa à conjugação dos fatores estritamente ambientais e de caráter técnico com o seu contexto social, econômico, cultural, ético e político. Reconhece os saberes e os fazeres populares, suas construções culturais sobre seu ambiente, como fatores determinantes no trato jurídico dos conflitos incidentes sobre os bens socioambientais e como fontes de construção e renovação do Direito Ambiental.

$\mathrm{Na}$ discussão que se pretende desenvolver, precisa haver clareza que o direito de povos e comunidades tradicionais está relacionado com o direito à territorialidade que remete, conforme Almeida ${ }^{11}$ à: "[...] identificação, defesa e força. Laços solidários de ajuda mútua informam um conjunto de regras firmadas sobre uma base física comum, essencial e inalienável [...]".

Por haver inúmeros povos e comunidades tradicionais, foi necessário definir aqueles com os quais se trabalharia. Para isso, vale-se de um critério jurídico, considerando apenas os povos e as comunidades tradicionais que tiveram o direito ao território resguardado legalmente, tanto pela Constituição Federal de 1988 quanto por leis infraconstitucionais. Ademais, concentra-se ainda naqueles localizados na Amazônia Legal, porquanto de acordo com Diegues ${ }^{12}$, 60\% das populações tradicionais indígenas e não indígenas vivem no bioma amazônico.

Com base nesse critério estabelecido, foram selecionadas três categorias de povos e comunidades tradicionais: povos indígenas, comunidades remanescentes

10 CAVEDON, Fernanda de Salles; VIEIRA, Ricardo Stanziola. Direito e multiculturalismo: a tensão entre regulação e emancipação. In: Novos Estudos Jurídicos. Universidade do Vale do Itajaí, Curso de Mestrado em ciências Jurídicas, Edição Especial. Itajaí: UNIVALI, 2006. p. 67. Em:< http://www6.univali.br/seer/index.php/nej/article/view/4484/2477 >. Acesso: 14 maio 2015.

11 ALMEIDA. Alfredo Wagner Berno de. Terras de quilombo, terras indígenas, 'babaçuais livres', 'castanhais do povo', faixinais e fundos de pasto: terras tradicionalmente ocupadas. Manaus: PPGSCA-UFAM, 2006. p. 101-102.

12 DIEGUES, Antonio Carlos. Água e cultura nas populações tradicionais brasileiras. 2007, p. 6. Trabalho apresentado no I Encontro Internacional: Governança da Água, São Paulo, nov. 2007. Em: <http://nupaub.fflch.usp.br/sites/nupaub.fflch.usp.br/files/color/ simbolagua.pdf>. Acesso em: 24maio 2015. 
de quilombolas e comunidades extrativistas tradicionais. Dada a extensão dessa última categoria, foi necessário concentrar as análises nos extrativistas cujo território foi reconhecido por meio de projetos de assentamento agroextrativistas e de unidades de conservação.

A abordagem metodológica do tema baseou-se em uma pesquisa teórica, com levantamento bibliográfico, doutrinário e legislativo das convenções internacionais e da literatura nacional. Também foi realizada a pesquisa de campo, com entrevistas abertas com técnicos da Secretaria de Estado de Meio Ambiente (SEMA), do Instituto Nacional de Colonização e Reforma Agrária (INCRA), do Instituto Chico Mendes de Conservação da Biodiversidade (ICMBio) e do Ministério do Meio Ambiente (MMA), para verificar como se dava a aplicação das referidas normas. Em seguida, analisaram-se as formas de regulamentação do reconhecimento do direito ao território por parte de povos e comunidades tradicionais e estudaramse seletivamente os procedimentos administrativos referentes a cada uma das categorias selecionadas, além de se comparar as referidas categorias.

Coletaram-se dados bibliográficos nas bibliotecas locais (Universidade Federal do Pará, Núcleo de Altos Estudos Amazônicos, Centro de Ciências Jurídicas), bem como no banco de dados deórgãos governamentais ou em seussites - principalmente doInstituto Brasileiro do Meio Ambiente e dos Recursos Naturais Renováveis (IBAMA), do ICMBio, da SEMA, do INCRA, da Fundação Cultural Palmares (FCP), do Departamento Nacional de Produção Mineral (DNPM), do MMA e do Ministério do Desenvolvimento Social e Combate à Fome (MDS) - e nos sites de algumas organizações não governamentais que trabalham com o tema, como o Instituto Socioambiental (ISA), a Comissão Pró-Índio (CPI) de São Paulo e, ainda, no site do Núcleo de Apoio à Pesquisa sobre Populações Humanas e Áreas Úmidas Brasileiras (NUPAUB).

O trabalho encontra-se dividido em três partes principais. Inicialmente se abordou sobre os direitos coletivos a partir dos direitos fundamentais. Em seguida, expôs-se a respeito dos institutos e dos instrumentos jurídicos que garantem o reconhecimento ao território por parte dos povos e das comunidades tradicionais. Posteriormente, analisaram-se comparativamente as normasjurídicas que permitem o reconhecimento aos territórios por parte de povos e comunidades tradicionais. 


\section{DIREITOS FUNDAMENTAIS COLETIVOS}

A Constituição Federal de $1988^{13}$ garante os direitos coletivos no âmbito dos direitos e das garantias fundamentais, no seu título II, capítulo I - dos direitos e deveres individuais e coletivos. Do rol dos direitos coletivos, destaca-se o meio ambiente ecologicamente equilibrado, considerado como patrimônio ambiental nacional e direito fundamental.

Sarlet ${ }^{14}$ informa que o rol dos direitos fundamentais indicados no artigo $5^{\circ}$ da Constituição Federal de 1988 é apenas exemplificativo, porquanto de acordo com o artigo $5^{\circ}, \$ 2^{\circ}$ outros se encontram presentes, tanto na própria Constituição como fora dela. Sendo este o caso do meio ambiente ecologicamente equilibrado, previsto no caput do seu artigo 225.

Referente aos direitos coletivos, foi o Código de Defesa do Consumidor ${ }^{15}$ que os definiu por meio do seu artigo 81. Com base nesse artigo, depreende-se que, para tratar de direitos coletivos, é preciso levar em consideração que direitos coletivos lato sensu referem-se ao gênero, composto por três categorias: o individual homogêneo, o coletivo stricto sensu e o difuso. O individual homogêneo é considerado acidentalmente coletivo; os demais - essencialmente coletivos são os que importam para o presente estudo.

Os essencialmente coletivos - o coletivo stricto sensu e o difuso - assemelhamse pelo aspecto objetivo, ou seja, pela indivisibilidade do bem, ambos se referem a objetos indivisíveis. O que os diferencia é o aspecto subjetivo: no caso dos direitos coletivos stricto sensu, os sujeitos são grupos, categorias ou classes de pessoas bem definidas por uma relação jurídica base; já nos direitos difusos os sujeitos são indeterminados e estão ligados não por relações jurídicas, mas por fatos.

13 BRASIL. Constituição da República Federativa do Brasil, de 5 de outubro de 1988. Diário Oficial [da] República Federativa do Brasil, Brasília, DF, 5 out. 1988a. Disponível em: < http://www.planalto.gov.br/ccivil_03/constituicao/constituicao.htm>. Acesso em: 24 maio 2015.

14 SARLET, Ingo Wolfgang. A eficácia dos direitos fundamentais. 9. ed. rev., atual. e ampl. Porto Alegre: Livraria do Advogado, 2008.

15 BRASIL. Lei n.0 8.078, de 11 de setembro de 1990. Diário Oficial [da] República Federativa do Brasil, Brasília, DF, 12 set. 1990. Retificado em: 10 jan. 2007. Disponível em: < http://www.planalto.gov.br/ccivil_03/leis//8078.htm>. Acesso em: 24 maio 2015. 
Povos e comunidades tradicionais compõem o patrimônio ambiental imaterial e em seus territórios há diversos bens ambientais naturais e culturais. Os naturais são o solo, a água, o ar, a fauna e a flora; os culturais incluem bens materiais, como os sítios arqueológicos, paleontológicos, ecológicos e científicos, e imateriais, como os modos de criar, fazer e viver dos povos e comunidades tradicionais.

Destarte, povos e comunidades tradicionais encontram-se protegidos por meio de direitos e deveres coletivos, pois ao se proteger de forma mediata o meio ambiente ecologicamente equilibrado, protege-se, de forma imediata, o bem ambiental cultural, do qual povos e comunidades tradicionais fazem parte.

Dessa forma, quando se propõe, neste artigo, a identificar e a analisar as normas jurídicas de acesso aos territórios por parte de povos e comunidades tradicionais, está se tratando de direitos coletivos lato sensu sob duplo aspecto: coletivo stricto sensu e difuso.

Ao se proteger o patrimônio ambiental nacional, protege-se o meio ambiente ecologicamente equilibrado, que é um objeto indivisível, cujo sujeito não pode ser determinado, e a relação que une o sujeito ao objeto será sempre fática. Está se referindo, portanto, a um direito coletivo da categoria difusa.

Por outro lado, os povos e as comunidades tradicionais devem ter reconhecido seu direito aos territórios tradicionais em que estão instalados. Trata-se de um direito coletivo da categoria coletiva stricto sensu: o sujeito - povos e comunidades tradicionais lá existentes - é determinado e está ligado ao bem por uma relação jurídica que, de acordo com as categorias aqui estudadas, inclui o reconhecimento do território indígena, a titulação das comunidades remanescentes de quilombos, a criação das Reserva Extrativista (RESEX), a Reserva de Desenvolvimento Sustentável (RDS), a Floresta Nacional (FLONA) e a criação de Projeto Agroextrativista (PAE); o objeto - territórios tradicionais e bens ambientais - é indivisível, porque pertence a todos do grupo. 


\section{INSTITUTOS E INSTRUMENTOS JURÍDICOS DE RECONHECIMENTO DO DIREITO AO TERRITÓRIO POR PARTE DE POVOS E COMUNIDADES TRADICIONAIS}

\section{POVOS INDÍGENAS}

O arranjo jurídico construído para garantir o acesso ao território por parte dos povos indígenas provocou muitas reflexões no âmbito jurídico, principalmente com foco em dois institutos tradicionais do direito civil: a propriedade e a posse, que passaram a ser confrontadas com o direito originário e com a posse permanente.

É cediço que a Constituição, ao reconhecer os direitos originários em relação às terras indígenas, admite tratar-se de direitos anteriores à criação do Estado brasileiro. Contudo, as críticas à posse permanente dos povos indígenas foram reforçadas ao se contrapor o direito originário deles ao instituto da posse civil e até da posse agrária.

Para Souza Filho ${ }^{16}$, a posse permanente não poderá ser comparada à civil, pelo fato de não se tratar de direito privado. Para ele, a terra indígena não é terra pública nem privada, também não se encaixa no direito de propriedade. Outra distinção citada pelo autor é o fato de a posse permanente poder ser usufruída coletivamente, enquanto as demais serão usufruídas individualmente, ou seja, com exclusividade ${ }^{17}$.

Sustenta-se que o direito originário dos índios está relacionado à territorialidade e a posse permanente, ao direito originário, diferindo, por isso, da posse civil e da posse agrária, ambas fundadas no direito de propriedade privada.

Por essa concepção, sustenta-se que nem o direito originário é direito de propriedade, nem a posse permanente poderá ser comparada às demais posses. 16 SOUZA FILHO, Carlos Frederico Marés de. 0 renascer dos povos indígenas para o direito. Curitiba: Juruá, 1999. p.131.

17 SOUZA FILHO, Carlos Frederico Marés de. 0 renascer dos povos indígenas para o direito. p.123. 
Quando se reconhece que as terras indígenas são bens da União, elas devem ser entendidas como bem público registrado no nome da União. Contudo, de todos os direitos relacionados à propriedade, o único que sobreviveu foi o de reivindicar as terras de quem as detenha injustamente.

Ratifica-se que o arranjo jurídico de reconhecimento dos territórios indígenas foi criativo ao garantir o direito originário sobre as terras tradicionalmente ocupadas, bem como ao atribuir o direito de propriedade à União e a posse permanente aos índios.

Nesse caso, além de afastar o receio de alguns quanto à integridade do território nacional, garantiu os direitos primários dos índios em relação aos seus territórios e ainda obrigou a União a garantir o uso e o gozo aos índios por meio da posse permanente e do usufruto indígena.

Impôs também à União a obrigação da defesa desses territórios, segundo Santilli ${ }^{18}$, tanto pela obrigação de defender os povos indígenas quanto pela obrigação de defender seu próprio patrimônio.

Dessa forma, sustenta-se que essa proteção está diretamente relacionada à obrigação do Poder Público em relação ao patrimônio ambiental nacional o meio ambiente ecologicamente equilibrado -, porque composto pelo bem ambiental cultural, do qual povos e comunidades tradicionais fazem parte. E a sobrevivência desses povos está diretamente relacionada à proteção dos seus territórios.

Ainda que a Constituição Federal tenha reconhecido as terras indígenas como de propriedade da União, impôs a esta a obrigação de garantir o uso e o gozo aos povos indígenas com base no direito originário. Por isso, os povos indígenas poderão usufruir de suas terras por meio de um novo instituto criado com o objetivo de atender a essa peculiaridade - a posse permanente. Esse novo instituto se concretizará com base no usufruto indígena; logo, o direito à territorialidade está garantido.

18 SANTILLI, Márcio. Natureza e situação da demarcação das terras indígenas no Brasil. In: KASBURG, Carola; GRAMKOW, Márcia Maria (Org.). Demarcando terras indígenas: experiências e desafios de um projeto de parceria. Brasília, DF: FUNAI; PPTAL; GTZ, 1999. p. 23. 
Mais uma vez, a Constituição Federal de 1988 previu um instrumento inovador - o usufruto indígena. Há que se ressaltar a diferença entre esse usufruto e o previsto no Código Civil. O usufruto indígena é originário, portanto anterior inclusive à propriedade, não se podendo aplicar-lhe qualquer norma. Também prescinde de registro em cartório, por decorrer de norma estatal de caráter constitucional. Trata-se de usufruto permanente, afastando-se mais uma vez do civil, que é de caráter temporário.

Outra característica que o distingue do usufruto convencional é o fato de ser transmitido aos sucessores, não em virtude da sucessão em si, mas em virtude da condição de índio e da previsão constitucional. Trata-se de um direito coletivo, pertencente às comunidades indígenas. Como as terras indígenas pertencem à União, esse usufruto é um direito das comunidades indígenas sobre coisas de propriedade alheia ${ }^{19}$.

Ademais, no que diz respeito ao direito de propriedade, a Constituição Federal de 88 declarou, por meio do artigo 20, inciso $\mathrm{XI}^{20}$, que as terras indígenas seriam de propriedade da União. Contudo, embora a União seja a proprietária das terras indígenas, delas não poderá usar, gozar, nem dispor, porquanto seu uso e seu gozo pertencem aos povos indígenas de forma permanente, trata-se de destinação constitucional.

Não obstante, verifica-se que os povos indígenas, apesar de poderem usar e gozar dessas terras, delas não poderão dispor, por não serem proprietários; também não poderão transferir a posse, salvo por hereditariedade, entendida como uma decorrência da condição de ser índio e não da sucessão em si. Essas medidas foram tomadas a fim de proteger seus territórios.

Nota-se que a Constituição de 88 criou novos institutos jurídicos para resguardar direitos coletivos, distintos, portanto, dos demais, criados para regulamentar relações privadas. Nesse sentido, não há como encontrar no direito civil ou mesmo no direito agrário amparo para essa nova realidade. Por 19 CAVALCANTE FILHO, João Trindade. Usufruto exclusivo das terras indígenas: natureza jurídica, alcance e objeto. Jus Navigandi, Teresina, ano 12, n. 1640, 28 dez. 2007. Disponível em: < http://jus.com.br/artigos/10804/usufruto-exclusivo-das-terras-indigenas >. Acesso em: 24 maio 2015.

20 BRASIL. Constituição da República Federativa do Brasil, de 5 de outubro de 1988. 
isso, muitas vezes os doutrinadores referem-se a esses novos institutos como sui generis, por fugirem às regras desenhadas para as relações jurídicas privadas.

\section{COMUNIDADES REMANESCENTES DE QUILOMBOS}

A forma jurídica encontrada pelo constituinte para assegurar às comunidades remanescentes de quilombos o direito ao território alterou o direito de propriedade no Brasil, ao instituir a propriedade comum, até então inexistente no ordenamento jurídico brasileiro.

Os doutrinadores advertem que não se pode comparar a propriedade civil com a propriedade comum. O direito de propriedade civil garante o direito exclusivo de usar, gozar e dispor da coisa e de reavê-la de quem a detenha injustamente. Já o direito de propriedade comum não é exclusivo, pois pertence a todos da comunidade. Além disso, o direito sobre esta propriedade é indisponível.

Tanto o artigo 215, § 1. ${ }^{\circ}$, quanto o artigo 216 da Constituição Federal de 88 fundamentam esse direito coletivo ${ }^{21}$. O primeiro impõe ao Estado o dever de proteger as manifestações culturais afro-brasileiras, porquanto elas participam do processo civilizatório nacional. O segundo inclui, no patrimônio cultural imaterial, os modos de criar, fazer e viver dos afro-brasileiros. Nesse caso, de acordo com os antropólogos 22 , esse uso sempre foi comum.

Acevedo Marin ${ }^{23}$ relaciona o patrimônio comum com a identidade social coletiva, cujo valor é simbólico, excedendo, portanto, o valor econômico; por 21 BRASIL. Constituição da República Federativa do Brasil, de 5 de outubro de 1988.

22 Nesse sentido: ALLEGRETTI, Mary Helena. A construção social de políticas ambientais: Chico Mendes e o movimento dos seringueiros. 2002. 827 f. Tese (Doutorado em Desenvolvimento Sustentável - Gestão e Política Social) - Centro de Desenvolvimento Sustentável de Brasília, Universidade de Brasília, Brasília, DF, 2002; ALMEIDA, Alfredo Wagner Berno de. Terras de preto, terras de santo, terras de índio: uso comum e conflito. In: CASTRO, Edna Maria Ramos de; Hébette, Jean (Org.). Na trilha dos grandes projetos. Belém: NAEA, UFPA, 1989. p. 163-196; DIEGUES, Antonio Carlos; MOREIRA, André de Castro C. (Org.). Espaços e recursos naturais de uso comum. São Paulo: Núcleo de Apoio à Pesquisa sobre Populações Humanas e Áreas Úmidas Brasileiras, USP, 2001; LITTLE, Paul E. Territórios sociais e povos tradicionais no Brasil: por uma antropologia da territorialidade. Brasília, DF, 2002, p. 4 (Série Antropologia, n. 322

23 ACEVEDO MARIN, Rosa Elizabeth. Julgados da terra: cadeia de apropriação e atores sociais em conflitos na ilha de Colares, Pará. Belém: UFPA, 2004. p. 201. 
isso a concepção de patrimônio comum elabora formas de direitos e obrigações em que a terra não é mercadoria.

Isso faz com que os títulos a serem entregues às comunidades remanescentes de quilombos sejam coletivos, em nome de uma associação que as represente, não sendo permitida sua negociação; caso contrário, o direito à cultura estaria ameaçado.

O direito de propriedade garantido aos quilombolas atualmente se encontra regulamentado por meio do Decreto n. ${ }^{\circ} 4.887 / 03^{24}$ e da Instrução Normativa do INCRA n. ${ }^{\circ} 49 / 08^{25}$ (INCRA, 2008). Ao analisar essas normas jurídicas, verifica-se que o título será coletivo e pró-indiviso, concedido à comunidade por meio de suas associações legalmente constituídas. Além disso, os títulos deverão inserir cláusulas de inalienabilidade, imprescritibilidade e impenhorabilidade ${ }^{26}$. Nessa direção, Sundfeld ${ }^{27}$ afirma: "Trata-se de atribuir a propriedade a uma pessoa coletiva, e não a pessoas individuais que formariam um emaranhado de títulos atribuídos separadamente".

Porfugiremàs regras desenhadas paraas relaçõesprivadas, essasnormasjurídicas são muitas vezes difíceis de serem compreendidas e aplicadas. $O$ depoimento de Braga ${ }^{28}$, advogado e consultor, durante o I Seminário Reconhecimento e Titulação das Terras de Quilombos no Município de Ubatuba, Estado de São Paulo, confirma isso: ele afirma ter enfrentado muitos problemas ao iniciar no INCRA o processo de regularização das áreas dos quilombolas, pois tiveram de ser pioneiros na

24 BRASIL. Decreto n.0 4.887, de 20 de novembro de 2003. Diário Oficial [da] República Federativa do Brasil, Brasília, DF, 21 nov. 2003. Disponível em: < http://www.planalto. gov.br/ccivil_03/decreto/2003/d4887.htm>. Acesso em: 24 maio. 2015.

25 INSTITUTO NACIONAL DE COLONIZAÇÃO E REFORMA AGRÁRIA (Brasil). Instrução Normativa n.0 49, de 29 de setembro de 2008. Diário Oficial [da] República Federativa do Brasil, Brasília, DF, 1 out. 2008. Disponível em: < http://www.planalto.gov.br/ccivil_03/ decreto/2003/d4887.htm>. Acesso em: 24 maio 2015.

26 SUNDFELD, Carlos Ari (Org.). Comunidades quilombolas: direito à terra. Brasília, DF: Fundação Cultural Palmares; MinC; Editorial Abaré, 2002. TRECCANI, Girolamo Domenico. Terras de quilombo: caminhos e entraves do processo de titulação. Belém: Programa Raízes, 2006. p. 81-82.

27 SUNDFELD, Carlos Ari (Org.). Comunidades quilombolas: direito à terra. 2002. p. 78.0000

28 BRAGA, Claudio Rodrigues. Mesa 2: Os procedimentos efetuados pelos órgãos públicos envolvidos com a titulação das terras de quilombos no município de Ubatuba. In: Leinad Ayer de (Org.). Quilombos: a hora e a vez dos sobreviventes. São Paulo: Comissão Pró-Índio de São Paulo, 2001. p. 99. 
concessão dos títulos - não existia nenhuma normatização para a aplicação do ADCT n. ${ }^{\circ} 68^{29}$ e os casos eram bastante diversificados.

É preciso deixar bem claro que, enquanto o direito de propriedade civil regula relações privadas, mantendo a exclusividade do direito de usar, gozar e dispor do bem e de reivindicá-lo de quem o detenha injustamente, o direito de propriedade comum regula relações coletivas, cujo fundamento encontra-se no direito à cultura. A posse oriunda da propriedade comum acompanha as suas características, refere-se, portanto, a direitos coletivos, e também não poderá ser comparada à posse civil nem à posse agrária. Trata-se, portanto, de uma nova modalidade de posse, cujo grande diferencial é o caráter coletivo. Para Benatti ${ }^{30}$, essa posse seria a agroecológica.

\section{COMUNIDADES EXTRATIVISTAS TRADICIONAIS}

As comunidades extrativistas tradicionais têm à sua disposição dois instrumentos que lhes garantem o acesso ao território: as unidades de conservação nas categorias de RESEX, RDS e FLONA e os projetos de assentamento na modalidade PAE.

Povos e comunidades tradicionais passaram a reivindicar o acesso aos territórios aos moldes dos territórios indígenas, ou seja, com o domínio das áreas que seriam da União e a posse por parte dos extrativistas, pois com isso impediriam a reprivatização da floresta por meio da venda de terras.

A luta empreendida resultou na criação de duas modalidades jurídicas: o projeto de assentamento extrativista em $1987^{31}$, como parte da política de reforma agrária; a criação das reservas extrativistas em 198932, como parte da política ambiental. É importante lembrar que, posteriormente, essas modalidades legais resguardarão - além dos direitos ao território dos extrativistas que exploravam 29 BRASIL. Constituição da República Federativa do Brasil, de 5 de outubro de 1988.

30 BENATTI, José Heder. Posse agroecológica e manejo florestal. Curitiba: Juruá, 2003.

31 INSTITUTO NACIONAL DE COLONIZAÇÃO E REFORMA AGRÁRIA (Brasil). Portaria n.0 627, de 30 de julho de 1987. Disponível em: < http://www.incra.gov.br/sites/default/files/uploads/ institucionall/legislacao--/portarias/portarias-de-1987/portaria_incra_p627_300787. pdf>. Acesso em: 24 maio 2015.

32 BRASIL. Decreto n. ${ }^{9}$ 98.897, de 30 de janeiro de 1990. Diário Oficial [da] República Federativa do Brasil, Brasília, DF, 31 jan. 1990. Disponível em: < http://www.planalto.gov. br/ccivil_03/decreto/Antigos/D98897.htm >. Acesso em: 24 maio 2015. 
a borracha - os direitos dos castanheiros, das quebradeiras de babaçu e das comunidades pesqueiras, entre outros.

Com o passar do tempo, essas duas modalidades foram alteradas. Hoje o projeto de assentamento extrativista ${ }^{33}$ foi substituído pelo $P A E$, regulamentado por meio das Portarias do INCRA $n^{\circ} 268^{34}$ e $n^{\circ} 269^{35}$. O órgão responsável pelo reconhecimento desses territórios na esfera federal é o INCRA e na estadual, no caso do Pará, é o ITERPA.

Quanto às unidades de conservação, observa-se que as RESEX passaram a compor em 2000 o sistema nacional de unidades de conservação criado por meio da Lei $n^{\circ}$ 9.985/0036. As RDS foram inicialmente criadas por iniciativa do Estado do Amazonas e, posteriormente, também passaram a ser absorvidas pela mesma lei. As FLONA foram previstas inicialmente na Lei $n^{\circ} 4.771$, de 15 de setembro de $1965^{37}$ e depois também se tornaram parte da Lei $n^{\circ} 9.985 / 00^{38}$.

O órgão competente para reconhecer os territórios de comunidades a serem resguardadas por meio da criação dessas unidades de conservação, na esfera federal, é o Instituto Chico Mendes de Conservação da Biodiversidade (ICMBio); na estadual e municipal, os órgãos similares ou os ambientais.

O reconhecimento dos territórios extrativistas tradicionais é garantido por meio de política ambiental e agrária. Quando os territórios são protegidos pela

33 INSTITUTO NACIONAL DE COLONIZAÇÃO E REFORMA AGRÁRIA (Brasil). Portaria n. ${ }^{\circ}$ 627, de 30 de julho de 1987.

34 INSTITUTO NACIONAL DE COLONIZAÇÃO E REFORMA AGRÁRIA (Brasil). Portaria n. ${ }^{\circ}$ 268, de 23 de outubro de 1996. Diário Oficial [da] República Federativa do Brasil, Brasília, DF, 25 out. 1996. Disponível em: <http://www.incra.gov.br/sites/default/files/uploads / institucionall/legislacao--/portarias/portarias-de-1996/portaria_incra_p268_231096.pdf>. Acesso em: 24 maio 2015.

35 INSTITUTO NACIONAL DE COLONIZAÇÃO E REFORMA AGRÁRIA (Brasil). Portaria n. 0 269, de 23 de outubro de 1996. Diário Oficial [da] República Federativa do Brasil, Brasília, DF, 25 out. 1996. Disponível em: <http://www.incra.gov.br/sites/default/files/uploads/ institucionall/legislacao--/portarias/portarias-de-1996/portaria_incra_p269_231096.pdf >. Acesso em: 24 maio 2015.

36 BRASIL. Lei n. ${ }^{\circ}$ 8.078, de 11 de setembro de 1990.

37 BRASIL. Lei n. ${ }^{0}$ 4.771, de 15 de setembro de 1965. Diário Oficial [da] República Federativa do Brasil, Brasília, DF, 16 set. 1965. Disponível em: < http://www.planalto.gov.br/ ccivil_03/leis/l4771.htm >. Acesso em: 24 maio 2015. Esta lei foi revogada pela Lei n. ${ }^{2} 12$. 651 de 2012. BRASIL. Lei n. 12.651, de 25 de maio de 2012. Diário Oficial [da] República Federativa do Brasil, Brasília, DF, 28 maio2012. Disponível em: < http://www.planalto. gov.br/ccivil_03/_Ato2011-2014/2012/Lei/L12651.htm\#art83>. Acesso em: 24 maio 2015. BRASIL. Lei n. 8.078, de 11 de setembro de 1990. 
política agrária, dispõem obrigatoriamente dos instrumentos dessa política, cuja competência é do INCRA (crédito, educação, saúde, infraestrutura). Quando recebem a proteção por via de política ambiental, a Norma de Execução $n^{\circ}$ $69^{39}$ deu ao INCRA a possibilidade de reconhecer as RESEX como projeto de assentamento, conforme será discutido mais à frente.

No caso tanto das unidades de conservação quanto dos assentamentos aqui tratados, o domínio da área será sempre da União e a posse será das comunidades extrativistas tradicionais. Essa propriedade e essa posse são distintas da civil, pois referida propriedade nunca será plena, porque a União jamais poderá usar, gozar nem dispor dela; e a posse, por sua vez, não será exercida pela União, somente pelas comunidades e de forma coletiva.

Além disso, previu-se também o contrato de direito real de uso. Porém, se o contrato de direito real de uso for celebrado entre o Poder Público e as comunidades extrativistas tradicionais, ele não deve ser interpretado com base no direito administrativo. Esse instrumento precisará ser interpretado com base na Constituição Federal de 1988 e nas normas de Direito Ambiental. Por isso, considera-se que houve a inserção de um novo instrumento - o contrato de direito real de uso coletivo, como se passa a denominá-lo.

Sabe-se que os territórios ocupados pelas comunidades extrativistas tradicionais aqui estudadas são de propriedade da União, conforme regulamentação anteriormente analisada. A propriedade de tais bens corresponde ao ente federal, mas são bens públicos de natureza sui generis, porquanto, mesmo que o direito de propriedade seja da União, a posse será sempre das comunidades, por tratar-se de bem ambiental cultural. Nesse caso, trata-se de bem inalienável e indisponível. É nesse contexto especial, em que a propriedade é da União e a posse coletiva é exercida por essas comunidades, que se deve entender o contrato de direito real de uso coletivo (CDRUC).

Ressalte-se que o CDRU possui características próprias, são elas: a) só poderá ser firmado entre a Administração Pública e as comunidades extrativistas tradicionais,

39 INSTITUTO NACIONAL DE COLONIZAÇÃO E REFORMA AGRÁRIA (Brasil). Norma de Execução n. ${ }^{\circ}$ 69, de 12 março de 2008. Diário Oficial [da] República Federativa do Brasil, Brasília, DF, 2008. Disponível em: <http://www.incra.gov.br/sites/default/files/uploads/ institucionall/legislacao--/atos-internos/normas/ne_69_120308.pdf>. Acesso em: 24 maio 2015. 
pois são territórios tradicionais; b) será sempre por prazo indeterminado (perpétuo); além disso, sendo perpétuo o direito, afasta-se a incidência de outras normas, como as relativas à sua extinção; c) trata-se de um direito coletivo, e não individual de cada comunitário; d) sua transmissão dá-se pela tradição; e) o direito ao território incide sobre toda a universalidade dos bens que formam os territórios tradicionais, o que inclui o solo ${ }^{40}$, a fauna e a flora; f) é gratuito.

Portanto, trata-se de contrato firmado entre o Poder Público e as comunidades extrativistas tradicionais, o qual reconhece a essas comunidades o direito de posse coletiva em territórios tradicionais, objetivando sua preservação e os meios para que possam alcançar seu desenvolvimento físico, econômico e cultural. Em outras palavras, o CDRUC consiste em um instrumento capaz de assegurar o acesso das comunidades extrativistas tradicionais aos seus territórios.

Destarte, mais uma vez, confirma-se a necessidade de sintonia entre os instrumentos criados para dar suporte ao acesso aos territórios por parte de povos e comunidades com os direitos coletivos inseridos pela Constituição Federal de $88^{41}$. Nesse caso, ainda que a lei indique o CDRU a ser utilizado, para ser aplicado, ele precisará levar em conta o direito coletivo, daí a denominação de CDRUC.

Verifica-se que houve a criação de um instituto e de três instrumentos como forma de reconhecer o acesso das comunidades extrativistas tradicionais aos territórios: a posse coletiva, as unidades de conservação (RESEX, RDS e FLONA), os assentamentos agroextrativistas (PAE) e o CDRUC.

Infere-se que a criação de unidades de conservação nas categorias de RESEX, RDS e FLONA e PAE revolucionou o sistema jurídico, porque deixou a propriedade para a União e a posse para as comunidades extrativistas tradicionais. Porém, ainda que a União tenha o direito de propriedade dessas áreas, sustenta-se que ela não poderá usar, gozar nem dispor delas, só poderá reivindicá-las de quem as detiver injustamente. Além do mais, está obrigada a destinar referidas áreas para o uso e o gozo das comunidades extrativistas tradicionais, por meio da posse coletiva. Logo, referidas áreas tornaram-se indisponíveis por se tratar de territórios tradicionais.

40 Com exceção apenas dos bens de dominialidade da União.

41 BRASIL. Constituição da República Federativa do Brasil, de 5 de outubro de 1988. 


\section{ANÁLISE COMPARATIVA DAS NORMAS JURÍDICAS DE RECONHECIMENTO DOS TERRITÓRIOS TRADICIONAIS}

\section{CARACTERÍSTICAS GERAIS COMUNS DOS INSTRUMENTOS E INSTITUTOS DE RECONHECIMENTO AOS TERRITÓRIOS} TRADICIONAIS

Considera-se como gerais as características comuns apresentadas nas normas referentes ao reconhecimento ao território por parte de povos e comunidades tradicionais aqui abordados: a base da proteção é o direito à cultura; as normas referem-se à proteção de direitos coletivos; a natureza jurídica dos institutos utilizados é coletiva.

A base da proteção de todos os povos e comunidades tradicionais é a mesma: é o direito à cultura, segundo o qual o direito ao território deverá obrigatoriamente ser reconhecido pelo Poder Público; caso contrário, o direito à cultura não estará sendo preservado. O reconhecimento por parte do Poder Público do direito ao território não implica o direito ao domínio, mas implica o direito à posse. Este último é considerado um instituto imprescindível, com características sui generis, porquanto a posse nesses territórios só poderá ser assegurada a povos e comunidades tradicionais e sempre de forma coletiva.

Portanto, com exceção das comunidades remanescentes de quilombos, todas as demais categorias aqui estudadas não dispõem do domínio, dispõem somente da posse. Contudo, este instituto da posse serve para garantir o direito ao território por parte das comunidades extrativistas tradicionais.

Mesmo as comunidades remanescentes de quilombos, que têm o direito de propriedade, não poderão dispor do bem, logo, a propriedade não será plena. Dessa forma, o legislador objetivou garantir a proteção do bem maior - a cultura. A propriedade foi garantida para que se mantenham os territórios tradicionais dos quilombolas e neles eles possam reproduzir-se econômica, social e culturalmente. 
É importante ressaltar que, se o Poder Público manteve a propriedade das áreas dos povos indígenas e das comunidades extrativistas tradicionais, esse domínio também é limitado, pois além de não poder usar e gozar dessas áreas, o Poder Público tampouco poderá dispor delas. Essas áreas só poderão ser reconhecidas como territórios dos povos e das comunidades tradicionais.

Verifica-se, portanto, que os territórios tradicionais foram retirados do mercado. Inexiste qualquer possibilidade de negociação em relação a eles, ou seja, nem o Poder Público nem os povos e comunidades tradicionais poderá dispor desses territórios. O uso e o gozo desses territórios serão sempre assegurados aos povos e às comunidades tradicionais, porquanto são imprescindíveis à manutenção do pluralismo cultural.

Para garantir o acesso aos territórios por parte de povos e comunidades tradicionais, foi necessário criar novos institutos jurídicos ${ }^{42}$ : para os índios, o direito originário e a posse permanente; para as comunidades remanescentes de quilombos, o direito à propriedade comum; para as comunidades extrativistas tradicionais, a posse coletiva e o contrato de direito real de uso coletivo.

Todos esses institutos são novos, pois ainda que existam institutos similares no direito privado, com eles não se confundem. Para que esses institutos possam ser mais bem implementados, precisam ser normatizados com base nos direitos coletivos.

No que diz respeito às comunidades extrativistas tradicionais, verifica-se que os PAE estão incorrendo em erro, porquanto submetem as comunidades extrativistas tradicionais ao processo de reforma agrária tradicional, à semelhança do se fez inicialmente para as comunidades remanescentes de quilombos.

Verifica-se que as comunidades remanescentes de quilombos atualmente têm o reconhecimento de seus territórios realizado pelo INCRA, que em momento algum submete esse reconhecimento ao licenciamento ambiental, uma vez que se trata não da criação de projetos de assentamento tradicionais, mas do reconhecimento do direito à propriedade ou à territorialidade.

42 Embora os referentes aos povos indígenas já existissem, diz-se que são novos porque deixaram para trás a política de integração nacional e passaram respeitar a sua cultura. 


\section{SEMELHANÇA ENTRE OS INSTRUMENTOS E OS INSTITUTOS DE RECONHECIMENTO DOS TERRITÓRIOS TRADICIONAIS}

A comparação dos institutos jurídicos que garantem o reconhecimento das categorias de povos e comunidades tradicionais estudadas ao território permite identificar as características particulares desses institutos.

Assim, os povos indígenas e as comunidades extrativistas tradicionais nunca terão a dominialidade dos territórios que ocupam, ela sempre pertencerá à União. Além disso, o direito de propriedade em relação a esses territórios não inclui a disponibilidade, portanto esses territórios são bens fora do mercado.

Apesar das semelhanças existentes, povos indígenas e comunidades extrativistas diferem em relação aos institutos jurídicos que resguardam seus direitos. Os povos indígenas têm o direito ao território garantido por meio do direito originário que lhes garante a posse permanente, enquanto as comunidades extrativistas tradicionais dispõem de quatro formas para o acesso ao território: RESEX, RDS, PAE e FLONA. Esta desde que as comunidades já estiverem presentes antes da sua criação.

Por outro lado, os povos indígenas têm direito à posse permanente, mas nunca terão direito à dominialidade, que sempre será da União; já as comunidades remanescentes de quilombos têm direito ao domínio e à posse. Entretanto, nem os povos indígenas nem as comunidades remanescentes de quilombos poderá dispor de suas áreas: para os povos indígenas, a indisponibilidade deve-se ao fato de as áreas serem de domínio da União e de posse permanente do povo indígena que lá se encontra; para as comunidades remanescentes de quilombos, a indisponibilidade resulta do fato de tratar-se de título concedido à associação que representa a coletividade, considerado como pró-indiviso e inalienável ${ }^{43}$.

43 Andrade e Treccani informam que a entrega do título a uma associação que representa os quilombolas foi a maneira encontrada para garantir a emissão do título coletivamente, uma vez que as comunidades não possuem personalidade jurídica. Porém dizem que nem sempre foi assim, houve necessidade de um grande esforço para convencer os técnicos do INCRA da possibilidade dessa titulação coletiva. ANDRADE, Lúcia; TRECCANI, Girolamo. Terras de quilombo. In: LARANJEIRA, Raymundo (Org.). Direito agrário brasileiro. São Paulo: LTr, 1999. p. 622. 
Chega-se a essa conclusão com base na leitura do artigo 68 do ADCT, porquanto ele faz referência a comunidades remanescentes de quilombos. Além disso, desejava-se permitir que essas comunidades se desenvolvessem econômica, social e culturalmente. Nesse caso, não poderia ser concedido título a um indivíduo, o título deve ser concedido à coletividade, que tem seus modos de criar, fazer e viver reconhecidos pela Constituição de $1988^{44}$.

No mesmo sentido, Sundfeld:

[...] A emissão do título de forma coletiva permite às comunidades quilombolas manter a forma pela qual exploram a terra e também a maneira pela qual estão organizadas. Tal preservação dos valores culturais e organizacionais do grupo é necessária, e se impõe pela importância com que tal tema é tratado em nossa Constituição Federal.

Porém, só hoje há clareza quanto a esses aspectos, antes difíceis de serem assimilados, pois se estava saindo do raciocínio privado para exercitar novos direitos - os coletivos, até então desconhecidos.

Ao se comparar os quilombolas com as comunidades extrativistas tradicionais, verifica-se que seu direito ao território é resguardado por institutos distintos: o dos quilombolas é resguardado pelo direito de propriedade comum; o das comunidades extrativistas tradicionais, pela criação de unidades de conservação (RESEX, RDS, FLONA) ou pela criação de PAE. No caso dos quilombolas, há transferência de domínio e posse, enquanto para os extrativistas há apenas a posse.

Todavia, tanto os territórios dos quilombolas quanto os das comunidades extrativistas tradicionais assemelham-se por serem propriedades que não podem ser disponibilizadas, nesse caso são bens fora do mercado. Outra semelhança: tanto o título de propriedade, no caso das comunidades quilombolas, quanto o CDRUC, no caso das comunidades extrativistas; são repassados a uma associação.

Por fim, a análise demonstra que há uma semelhança entre todos os institutos, independentemente da categoria: a preocupação do legislador, em todos os casos,

44 SUNDFELD, Carlos Ari (Org.). Comunidades quilombolas: direito à terra. Brasília, DF: Fundação Cultural Palmares; MinC; Editorial Abaré, 2002. p. 81. 
foi garantir que as referidas áreas tenham um fim específico, que não pode ser alterado, ou seja, as áreas devem ser usadas apenas por povos e comunidades tradicionais, objetivando o seu desenvolvimento cultural, social e econômico.

Portanto, vedou-se qualquer possibilidade de negociação em relação às áreas, que foram retiradas do mercado. Dessa forma, ainda que a Constituição Federal só tenha garantido o direito de propriedade comum aos quilombolas, há institutos de importância similar para as demais categorias estudadas, porquanto também as terras que ocupam foram retiradas do mercado. Sendo o domínio conferido à União, ela também estará obrigada a cuidar desse patrimônio, que ao mesmo tempo é seu (público), dos povos e das comunidades tradicionais (coletivo stricto sensu) e de toda a humanidade (difuso).

\section{CONSIDERAÇÕES FINAIS}

Ao término da análise, constatou-se haver necessidade de ajustes para que as normas relativas ao acesso de povos e comunidades tradicionais ao território possam de fato beneficiá-los. Pode-se afirmar que os principais fatores que dificultam a aplicação dessas normas é a percepção: a) do bem ambiental cultural como parte do patrimônio ambiental nacional; b) do fundamento do acesso ao território e aos bens ambientais está no direito coletivo; c) do fato do direito à territorialidade está desassociado do direito de propriedade;

No que se refere à falta de clareza em relação ao bem ambiental cultural considerado como parte do patrimônio ambiental nacional, observou-se que o fundamento da proteção de povos e comunidades tradicionais passou a ser o direito ambiental, mais precisamente o direito à cultura. Essa proteção possui duas camadas: a primeira garante a esses povos o respeito às suas manifestações e aos seus modos de criar, fazer e viver; a segunda incluiu-os como parte do patrimônio ambiental nacional. Portanto, são protegidos coletiva e difusamente.

Referente ao fundamento do reconhecimento ao território, houve uma mudança de paradigma do direito privado para o direito coletivo. Portanto, as novas relações jurídicas tomaram por base povos e comunidades tradicionais 
como sujeitos determinados, ligados juridicamente a um bem indivisível: seus territórios. Isso provocou resistência por parte dos ortodoxos, que sempre tiveram dificuldade de conceber o direito sem individualizar seus sujeitos e de lidar com bens que não podem ser apropriados individualmente.

O ordenamento jurídico no passado era desenhado para atender apenas sujeitos individuais, com bens divisíveis. Porém, com o passar do tempo e diante da demanda da sociedade, foi preciso garantir direitos coletivos. Para isso, lançouse mão de instrumentos jurídicos inovadores e distintos daqueles que garantem direitos privados. Daí decorre parte das dificuldades para aplicar as normas aqui analisadas e até para regulamentá-las.

Quanto à inserção do direito à territorialidade, verificou-se que povos e comunidades tradicionais têm direito ao território com base no direito à cultura. Nesse caso, outro aspecto relevante é o fato de que os institutos estão relacionados não à propriedade, mas aos territórios. Além disso, o acesso aos territórios é feito por meio da posse. Portanto, para povos e comunidades tradicionais, o direito de propriedade não é relevante; é relevante o direito ao território e o direito à posse, dos quais as comunidades são dependentes, sem eles não há como garantir o direito à cultura.

Verifica-se, portanto, que é o direito à cultura que garante aos povos e às comunidades tradicionais o direito ao território. Todos os territórios tradicionais são bens fora do mercado, o que evita que eles tenham valor de troca, ficando preservados como meio para o desenvolvimento econômico, social e cultural dos povos e comunidades tradicionais.

A natureza jurídica dos territórios tradicionais pode variar. Quando considerados como parte do patrimônio ambiental nacional, sua natureza é difusa; porém, quando considerados como bens ambientais culturais, sua natureza será coletiva.

Além disso, há resistência à aceitação do direito das minorias; afinal de contas, aceitar significa imobilizar uma parte de patrimônios, que deixarão de circular no mercado. A ideia aqui foi retirar o bem do mercado, para assegurar a sua proteção. 
Verifica-se que há muito a avançar, para isso será imprescindível reconhecer que se está diante de direitos coletivos em que: os sujeitos são grupos claramente definidos e ligados por relações jurídicas a bens que não serão divididos e, ao mesmo tempo, difusos porque protegidos como parte do patrimônio ambiental nacional - o meio ambiente ecologicamente equilibrado.

\section{REFERÊNCIAS}

ACEVEDO MARIN, Rosa Elizabeth. Julgados da terra: cadeia de apropriação e atores sociais em conflitos na ilha de Colares, Pará. Belém: UFPA, 2004, p. 201.

ANDRADE, Lúcia; TRECCANI, Girolamo. Terras de quilombo. In: LARANJEIRA, Raymundo (Org.). Direito agrário brasileiro. São Paulo: LTr, 1999. p. 593-656.

ALLEGRETTI, Mary Helena. A construção social de políticas ambientais: Chico Mendes e o movimento dos seringueiros. 2002. 827 f. Tese (Doutorado em Desenvolvimento Sustentável - Gestão e Política Social) - Centro de Desenvolvimento Sustentável de Brasília, Universidade de Brasília, Brasília, DF, 2002.

ALMEIDA, Alfredo Wagner Berno de. Terras de quilombo, terras indígenas, 'babaçuais livres', 'castanhais do povo', faixinais e fundos de pasto: terras tradicionalmente ocupadas. Manaus: PPGSCA-UFAM, 2006.

BENATTI, José Heder. Posse agroecológica e manejo florestal. Curitiba: Juruá, 2003.

BRAGA, Claudio Rodrigues. Mesa 2: Os procedimentos efetuados pelos órgãos públicos envolvidos com a titulação das terras de quilombos no município de Ubatuba. In: Leinad Ayer de (Org.). Quilombos: a hora e a vez dos sobreviventes. São Paulo: Comissão Pró-Índio de São Paulo, 2001.

BRASIL. Constituição da República Federativa do Brasil, de 5 de outubro de 1988. Diário Oficial [da] República Federativa do Brasil, Brasília, DF, 5 out. 1988. Disponível em: < http:// www.planalto.gov.br/ccivil_03/constituicao/constituicao.htm >. Acesso em: 22 set. 2013.

BRASIL. Decreto n. ${ }^{\circ}$ 98.897, de 30 de janeiro de 1990. Diário Oficial [da] República Federativa do Brasil, Brasília, DF, 31 jan. 1990. Disponível em: < http://www.planalto.gov.br/ccivil_03/decreto/ Antigos/D98897.htm >. Acesso em: 24 maio 2015. 
BRASIL. Lei n. ${ }^{\circ} 4.771$, de 15 de setembro de 1965. Diário Oficial [da] República Federativa do Brasil, Brasília, DF, 16 set. 1965. Disponível em: < http://www.planalto.gov.br/ccivil_03/ leis/l4771.htm >. Acesso em: 24 maio 2015.

BRASIL. Decreto n. ${ }^{\circ} 4.887$, de 20 de novembro de 2003. Diário Oficial [da] República Federativa do Brasil, Brasília, DF, 21 nov. 2003. Disponível em: < http://www.planalto.gov.br/ ccivil_03/decreto/2003/d4887.htm>. Acesso em: 24 maio. 2015.

BRASIL. Lei n. ${ }^{\circ}$ 7.347, de 24 de julho de 1985. Diário Oficial [da] República Federativa do Brasil, Brasília, DF, 25 jul. 1985. Disponível em: < http://www.planalto.gov.br/ccivil_03/leis/ 17347orig.htm>. Acesso em: 22 set. 2013.

BRASIL. Lei n. ${ }^{\circ} 8.078$, de 11 de setembro de 1990. Diário Oficial [da] República Federativa do Brasil, Brasília, DF, 12 set. 1990a. Retificado em: 10 jan. 2007. Disponível em: < http://www. planalto.gov.br/ccivil_03/leis/l8078.htm>. Acesso em: 24 maio 2015.

BRASIL. Lei n. ${ }^{\circ}$ 9.985, de 18 de julho de 2000. Diário Oficial [da] República Federativa do Brasil, Brasília, DF, 19 jul. 2000. Disponível em:< http://www.planalto.gov.br/ccivil_03/leis/ 19985.htm>. Acesso em: 22 set. 2013.

BRASIL. Lei n. ${ }^{\circ}$ 12.651, de 25 de maio de 2012. Diário Oficial [da] República Federativa do Brasil, Brasília, DF, 28 maio2012. Disponível em: < http://www.planalto.gov.br/ccivil_03/_ Ato2011-2014/2012/Lei/L12651.htm \#art83 >. Acesso em: 24 maio 2015.

CAVALCANTE FILHO, João Trindade. Usufruto exclusivo das terras indígenas: natureza jurídica, alcance e objeto. Jus Navigandi, Teresina, ano 12, n. 1640, 28 dez. 2007. Disponível em: < http://jus.com.br/artigos/10804/usufruto-exclusivo-das-terras-indigenas >. Acesso em: 24 maio 2015.

CAVEDON, FERNANDA SALLES; VIEIRA, RICARDO STANZIOLA. A política jurídica e o direito socioambiental: uma conribuição para a decidibilidade dos conflitos jurídico-ambietais. In: Revista NEJ - Eletrônica, v. n. p. 60-70/Edição Especial 2011. Disponível em: <www.univali. br/periódicos>. Acesso em: 14 de maio 2015.

DIEGUES, Antonio Carlos Sant'Ana; MOREIRA, André de Castro C. (Org.). Espaços e recursos naturais de uso comum. São Paulo: Núcleo de Apoio à Pesquisa sobre Populações Humanas e Áreas Úmidas Brasileiras, USP, 2001.

INSTITUTO CHICO MENDES DE CONSERVAÇÃO DA BIODIVERSIDADE. Instrução Normativa n. ${ }^{\circ}$ 
3, de 18 de setembro de 2007. Diário Oficial [da] República Federativa do Brasil, Brasília, DF, 20 set. 2007. Disponível: <http://nupaub.fflch.usp.br/sites/nupaub.fflch.usp.br/files/color/ simbolagua.pdf $>$. Acesso em: 24maio 2015.

INSTITUTO NACIONAL DE COLONIZAÇÃO E REFORMA AGRÁRIA (Brasil). Portaria n. ${ }^{\circ}$ 627, de 30 de julho de 1987. Disponível em: < http://www.incra.gov.br/sites/default/files/uploads/ institucionall/legislacao--/portarias/portarias-de-1987/portaria_incra_p627_300787.pdf > . Acesso em: 24 maio 2015.

INSTITUTO NACIONAL DE COLONIZAÇÃO E REFORMA AGRÁRIA (Brasil). Portaria n. ${ }^{\circ} 268$, de 23 de outubro de 1996. Diário Oficial [da] República Federativa do Brasil, Brasília, DF, 25 out. 1996a. Disponível em: < http://www.incra.gov.br/sites/default/files/uploads/ institucionall/legislacao--/portarias/portarias-de-1996/portaria_incra_p268_231096.pdf>. Acesso em: 24 maio 2015.

INSTITUTO NACIONAL DE COLONIZAÇÃO E REFORMA AGRÁRIA (Brasil). Portaria n. ${ }^{\circ} 269$, de 23 de outubro de 1996. Diário Oficial [da] República Federativa do Brasil, Brasília, DF, 25 out. 1996. Disponível em: < http://www.incra.gov.br/sites/default/files/uploads/institucionall/ legislacao--/portarias/portarias-de-1996/portaria_incra_p269_231096.pdf >. Acesso em: 24 maio 2015.

INSTITUTO NACIONAL DE COLONIZAÇÃO E REFORMA AGRÁRIA (Brasil). Instrução Normativa n. ${ }^{\circ}$ 49, de 29 de setembro de 2008. Diário Oficial [da] República Federativa do Brasil, Brasília, DF, 1 out. 2008a. Disponível em: < http://www.planalto.gov.br/ccivil_03/decreto/2003/ d4887.htm >. Acesso em: 24 maio 2015.

INSTITUTO NACIONAL DE COLONIZAÇÃO E REFORMA AGRÁRIA. Norma de Execução n. ${ }^{\circ}$ 69, de 12 março de 2008. Diário Oficial [da] República Federativa do Brasil, Brasília, DF. 2008. Disponível em: < http://www.incra.gov.br/sites/default/files/uploads/institucionall/ legislacao--/atos-internos/normas/ne_69_120308.pdf>. Acesso em: 24 maio 2015.

LITTLE, Paul E. Territórios sociais e povos tradicionais no Brasil: por uma antropologia da territorialidade. Brasília, DF, 2002 (Série Antropologia, n. 322). Disponível em: < http://nute. ufsc.br/bibliotecas/upload/paullittle.pdf>. Acesso em: 24 maio 2015.

LOPES, Syglea Rejane Magalhães Lopes. Reconhecimento aos índios do direito originário sobre as terras que tradicionalmente ocupam: raposa serra do sol. In: Revista da Faculdade de Direito da UFG. v. 37, n. 2. Goiás: UFG, 2013. p. 66-105. Em: < http://revistas.ufg.br/index. php/revfd/article/view/ 24055/16357> . Acesso em: 24 maio 2015 
PINTO, Felipe Chiarello de Souza; MENEZES, Daniel Francisco Nagao. Direito e multiculturalismo: a tensão entre regulação e emancipação. In: Revista NEJ - Eletrônica, v. 18, n.1, p. 63-73, janabr. 2013. Disponível em: <www.univali.br/periódicos>. Acesso em: 14 de maio 2015.

SANTILLI, Márcio. Natureza e situação da demarcação das terras indígenas no Brasil. In: KASBURG, Carola; GRAMKOW, Márcia Maria (Org.). Demarcando terras indígenas: experiências e desafios de um projeto de parceria. Brasília, DF: FUNAI; PPTAL; GTZ, 1999. p. 23-44.

SARLET, Ingo Wolfgang. A eficácia dos direitos fundamentais. 9. ed. rev., atual. e ampl. Porto Alegre: Livraria do Advogado, 2008.

SILVA, Larissa Tenfen. O multiculturalismo e a política de reconhecimento de Charles Taylor. In: Novos Estudos Jurídicos. v.11, n. 2. Itajaí: UNIVALI. p. 313-322, jun./dez. 2006. Em: < http:// www6.univali.br/seer/index.php/nej/article/view/440/382 >. Acesso em: 24 maio 2015.

SOUZA FILHO, Carlos Frederico Marés de. $\mathbf{O}$ renascer dos povos indígenas para o direito. Curitiba: Juruá, 1999.

SUNDFELD, Carlos Ari (Org.). Comunidades quilombolas: direito à terra. Brasília, DF: Fundação Cultural Palmares; MinC; Editorial Abaré, 2002.

TRECCANI, Girolamo Domenico. Terras de quilombo: caminhos e entraves do processo de titulação. Belém: Programa Raízes, 2006.

Recebido em: jun/2015

Aprovado em: abr/2016 